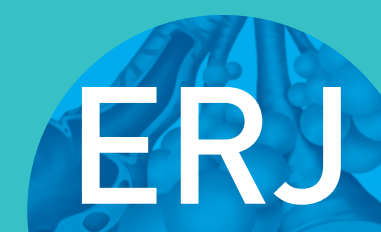

open research

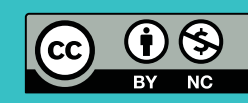

\section{Is there an association between altered baroreceptor sensitivity and obstructive sleep apnoea in the healthy elderly?}

\author{
Emilia Sforza ${ }^{1}$, Magali Saint Martin ${ }^{1,2}$, Jean Claude Barthélémy ${ }^{1}$ and \\ Frédéric Roche ${ }^{1}$
}

Affiliations: 'Service de Physiologie Clinique et de l'Exercice, Pole NOL, CHU, EA SNA-EPIS, Faculté de Médecine J. Lisfranc, UJM Saint-Etienne, PRES Université de Lyon, Saint-Etienne, France. ${ }^{2}$ Centre Hélio Marin de la Côte D'Azur, Hyeres, France.

Correspondence: Emilia Sforza, Service de Physiologie Clinique, EFCR, CHU Nord, Niveau 6, F-42055 Saint-Etienne Cedex 2, France. E-mail: emilia.sforzadgmail.com

ABSTRACT Obstructive sleep apnoea (OSA) is associated with a rise in cardiovascular risk in which increased sympathetic activity and depressed baroreceptor reflex sensitivity (BRS) have been proposed. We examined this association in a sample of healthy elderly subjects with unrecognised OSA.

801 healthy elderly (aged $\geqslant 65$ years) subjects undergoing clinical, respiratory polygraphy and vascular assessment were examined. According to the apnoea-hypopnoea index (AHI), the subjects were stratified into no OSA, mild-moderate OSA and severe OSA cases.

OSA was present in $62 \%$ of the sample, $62 \%$ being mild-moderate and $38 \%$ severe. No differences were found for BRS value according to sex and OSA severity. 54\% of the group had normal BRS value, 36\% mild impairment and 10\% severe dysfunction. BRS was negatively associated with body mass index $(\mathrm{p}=0.006), 24-\mathrm{h}$ systolic $(\mathrm{p}=0.001)$ and diastolic pressure $(\mathrm{p}=0.001)$, and oxygen desaturation index (ODI) $(\mathrm{p}=0.03)$. Regression analyses revealed that subjects with lower BRS were those with hypertension (OR $0.41,95 \%$ CI $0.24-0.81 ; \mathrm{p}=0.002$ ) and overweight (OR 0.42, 95\% CI 0.25-0.81; $\mathrm{p}=0.008$ ), without the effect of AHI and ODI.

In the healthy elderly, the presence of a severe BRS dysfunction affects a small amount of severe cases without effect on snorers and mild OSA. Hypertension and obesity seem to play a great role in BRS impairment.

@ERSpublications

In the healthy elderly with unrecognised OSA, the risk of blunted baroreceptor sensitivity was low http://ow.ly/kofu302IZWS

Received: June 272016 | Accepted: July 242016

Clinical trial: This study is registed at www.clinicaltrials.gov with identifier numbers NCT00759304 and NCT00766584.

Support statement: This study was supported by a grant from the French Ministry of Health (Cellule Projet Hospitalier de Recherche Clinique National, Direction de la Recherche Clinique, CHU Saint-Etienne; Appel d'Offre 1998 and Appel d'Offre 2002) and by a grant from "L'Association de Recherche SYNAPSE". Funding information for this article has been deposited with the Open Funder Registry.

Conflict of interest: None declared.

Copyright $\odot$ ERS 2016. This article is open access and distributed under the terms of the Creative Commons Attribution Non-Commercial Licence 4.0. 


\section{Introduction}

Obstructive sleep apnoea (OSA) is a common disease affecting $9 \%$ of women and $24 \%$ of men aged 30-60 years [1], with an even higher prevalence reported in the elderly population (aged $>65$ years). In the latter group, 24-62\% suffered from a mild form and 19-44\% represented moderate-severe cases [2-4]. Epidemiological studies demonstrated a strong link between OSA and cardiovascular diseases such as hypertension [5-7], coronary arterial disease, arrhythmias and heart failure [8]. Several mechanisms have been proposed to play a key role in the association between OSA and cardiovascular disease, including oxidative stress, inflammation and in particular the rise of sympathetic tonus in response to chemoreceptor stimulation by apnoea-related intermittent hypoxia [8-11]. A controversial point on the pathophysiology of vascular OSA consequence is the influence of a more complex dysregulation of the autonomic nervous system including both an increase of sympathetic activity and an impaired and/or suppressed spontaneous cardiac baroreflex sensitivity (BRS), a marker of parasympathetic activity that prevents the reflex rise of arterial blood pressure along the obstructive apnoea [12]. In the study of HeSSE et al. [13] considering healthy subjects, BRS was inversely correlated with mean 24-h blood pressure values. Few studies are present in the literature that consider the link between BRS and OSA severity. In middle-aged adult patients, a BRS dysfunction has been found in some OSA cases $[14,15]$, frequently in severe cases [16, 17], but not in mild OSA patients [18] or in snorers [19, 20].

To our knowledge, no data are presented in the literature concerning a possible association between altered BRS and OSA in the healthy elderly. Reduced BRS has been reported in older subjects due to the age-related reduction in cardiac parasympathetic tone [21,22] and increased basal sympathetic nerve activity [23]. Since age in itself may blunt the BRS response, we would expect a greater association between BRS and OSA in an older population. The purpose of the present study was two-fold in order to assess the following: 1) if there was an independent association between BRS and OSA in a homogenous large group of healthy elderly with unrecognised OSA; and 2) the potential contribution of other factors, such as overweight, smoking habit [24] and alcohol consumption [25], which are known to affect autonomic system regulation.

\section{Materials and methods \\ Participants}

Subjects were selected from the participants of a population-based cohort of 1011 volunteers aged $\geqslant 65$ years residing in the city of Saint-Etienne (France). The cases were enrolled in the PROOF (PROgnostic indicator OF cardiovascular and cerebrovascular events) [26] survey, an ongoing study on the prognostic value of autonomic nervous system activity indicators on cerebrovascular and cardiovascular morbidity and mortality. Exclusion criteria were defined as follows: age $<65$ years, previous reported myocardial infarction, arrhythmia, cardiac pacemaker, stroke, previous diagnosis of neurological or psychiatric disease, insulin-dependent diabetes, chronic obstructive pulmonary, renal or liver disease, cerebral magnetic resonance imaging suggesting neurological disease or initial dementia and currently living in an institution. Of the 3983 eligible participants, the final PROOF study included 1011 volunteers (609 females and 402 males). An ancillary study (Autonomic Nervous System Activity, Aging and Sleep Apnea/Hypopnea (SYNAPSE)) focusing on the association between OSA, as assessed by home-based polygraphy and cardiovascular consequences, was proposed to the participants, and the final sample was of 825 subjects. After exclusion of subjects who refused BRS measurement or home polygraphy, the final sample of 801 subjects aged $66.9 \pm 0.9$ years underwent a complete evaluation, including clinical interview, anthropometric measurements, 24-h blood pressure measurement, BRS assessment and ambulatory respiratory polygraphy.

The PROOF and the SYNAPSE studies were approved by the university hospital and the local ethics committee (CCPRB, Rhone-Alpes Loire, France). The French National Committee for Information and Liberty gave consent for data collection. All subjects gave their written consent prior to participation in the study.

\section{Clinical and instrumental assessments}

\section{Clinical assessment}

Clinical evaluation was assessed by a structured interview, which included history of cardiac and cerebrovascular diseases, arterial hypertension, diabetes and neurological and psychiatric disorders. Subjects were defined as normotensive if they did not report a history of hypertension and antihypertensive treatment and did not have a clinical measurement of systolic blood pressure (SBP) $>135 \mathrm{mmHg}$ and a diastolic blood pressure (DBP) $>85 \mathrm{mmHg}$ [27]. Habitual and past smoking, alcohol consumption ( $>2$ glasses of wine and/or spirit per day) and medications were analysed, with the latter focusing on antihypertensive, antidiabetic and antihypercholerolaemic medications by analysing medical prescriptions.

Anthropometric measurements

Anthropometric measurements included body mass index (BMI) and neck circumference, measured for all subjects. BMI was calculated as body weight divided by the square of height $\left(\mathrm{kg} \cdot \mathrm{m}^{-2}\right)$. We classified the 
subjects into three groups on the basis of BMI value: normal weight for BMI $<25 \mathrm{~kg} \cdot \mathrm{m}^{-2}$; overweight for BMI $>25 \mathrm{~kg} \cdot \mathrm{m}^{-2}$ and $<30 \mathrm{~kg} \cdot \mathrm{m}^{-2}$; and obese for BMI $>30 \mathrm{~kg} \cdot \mathrm{m}^{-2}$. neck circumference was measured at the middle of the neck between the mid-cervical spine and the mid-anterior neck $0.5 \mathrm{~cm}$ below the laryngeal prominence.

\section{Blood pressure assessment}

Diurnal SBP and DBP were measured by a physician using a standard mercury sphygmomanometer on the right arm while the subject was in the supine position following a 5-min period of rest. Ambulatory blood pressure monitoring was assessed over a 24-h period by an ambulatory recording device using an auscultatory method (Diasys Integra; Novacor, Rueil-Malmaison, France); the measurements were taken at 15-min intervals during the day and every $30 \mathrm{~min}$ during the night, with cuff placement on the nondominant arm. Diurnal and nocturnal periods were defined on the basis of the reported time when participants were lying down with the lights switched off. Subjects were defined as normotensive if no history of hypertension or antihypertensive treatment was reported, and if the 24-h ambulatory blood pressure monitoring did not show a diurnal mean SBP $\geqslant 135 \mathrm{mmHg}$ and a mean DBP $\geqslant 85 \mathrm{mmHg}$ [28].

\section{Measurement of BRS}

Spontaneous cardiac BRS was calculated over $15 \mathrm{~min}$ at rest in the supine position under the control of a doctor checking that the subjects did not move during the examination. Although the vasoactive drug bolus technique is widely used, the spontaneous method provides a reliable low stress and painless assessment of human vagal cardiac baroreflex activity. Finger arterial blood pressure was measured by the volume-clamp method by means of a noninvasive continuous blood pressure monitor (Finapres 2300; Ohmeda, Amsterdam, The Netherlands). For the calculation of BRS using the sequence method, the software listed all sequences of at least three or more successive heart beats in which there were concordant increases and decreases in SBP, and the R-R interval. For each sequence, linear regression slope was calculated. Then the BRS (expressed in $\mathrm{ms} \cdot \mathrm{mmHg}^{-1}$ ) was calculated as the mean of the slopes of all the sequences. Such a sequence method has been already used in our laboratory in post-myocardial infarction patients as well as in chronic obstructive pulmonary disease. For the last study [28], we determined normal range values of BRS in healthy 67 -year-old volunteers $\left(7.8 \pm 4.9 \mathrm{~ms} \cdot \mathrm{mmHg}^{-1}\right)$. In chronic obstructive pulmonary disease patients as well as in high-risk post-myocardial infarction patients, the mean value of BRS was $3.4 \pm 2.6$ and $3.1 \pm 2.1 \mathrm{~ms} \cdot \mathrm{mmHg}^{-1}$, respectively. In accordance with thresholds of BRS proposed in the Autonomic Tone and Reflexes After Myocardial Infarction (ATRAMI) study, we classified our sample according to a mean slope $<3 \mathrm{~ms} \cdot \mathrm{mmHg}^{-1}$ as a severe alteration of the cardiac baroreflex, a mean slope between $3-6 \mathrm{~ms} \cdot \mathrm{mmHg}^{-1}$ as a moderate alteration and a mean slope $>6 \mathrm{~ms} \cdot \mathrm{mmHg}^{-1}$ as a normal BRS range.

\section{Ambulatory home polygraphy}

All subjects underwent a full night ambulatory polygraphic recording using a polygraphic system (HypnoPTT; Medtronic, Dublin, Ireland). The following parameters were included: sound measurement, electrocardiography, pulse transit time, R-R timing, nasal pressure, respiratory effort and body position. Oxygen saturation was measured by pulse oximetry $\left(\mathrm{SpO}_{2}\right)$. To minimise potential overestimation of sleep duration, subjects completed the St. Mary's Hospital questionnaire, while wakefulness before lights off was excluded by the analysis. All examinations were visually validated and manually scored for respiratory events and nocturnal $\mathrm{SpO}_{2}$ by a single scorer (F. Roche), with an intrascorer reliability of $87 \%$. Hypopnoea was defined as a $\geqslant 50 \%$ reduction in airflow from the baseline value lasting $\geqslant 10 \mathrm{~s}$ and associated with $\geqslant 3 \%$ oxygen desaturation. Apnoea was defined as the absence of airflow in the nasal cannula lasting for $\geqslant 10 \mathrm{~s}$. The absence of rib cage movements associated with apnoea defined the event as central, while a progressive increase in pulse transit time and respiratory efforts allowed definition of the episode as obstructive. Apnoea-hypopnoea index (AHI) was defined as the ratio of the number of obstructive apnoeas and hypopnoeas per hour of reported sleeping time. The indices of nocturnal hypoxaemia were as follows: mean $\mathrm{SpO}_{2}$; percentage of recording time with a $\mathrm{SpO}_{2} \leqslant 90 \%$; minimum $\mathrm{SpO}_{2}$ value recorded during sleep (minimum $\mathrm{SpO}_{2}$ ); and oxygen desaturation index (ODI), i.e., the number of episodes of oxyhaemoglobin desaturation per hour of reported sleep time during which blood oxygen level fell $\geqslant 3 \%$. Pulse transit time was continuously monitored, and autonomic respiratory-related and total autonomic arousal indices were calculated after visual correction [29]. According to recent data in elderly subjects [30], an AHI $\geqslant 15$ events. $h^{-1}$ with at least $50 \%$ of events scored as obstructive was considered diagnostic of OSA. Cases were subsequently stratified as mild-to-moderate (AHI $\geqslant 15$ events. $h^{-1}$ and $<30$ events.h ${ }^{-1}$ ) and severe OSA cases (AHI $\geqslant 30$ events $\cdot h^{-1}$ ).

\section{Statistical analyses}

Study population characteristics were reported as mean $\pm \mathrm{SD}$ for continuous variables, and counts and percentages for categorical variables. Differences between men and women were assessed with the 
Chi-squared test for categorical variables and t-test for continuous variables. ANOVA with Bonferroni's correction for multiple comparisons was used to estimate differences between groups stratified according to AHI and type of BRS. Pearson's correlation analysis was done to evaluate the link between BRS value and clinical and polygraphic data. Multivariate regression analysis was performed where the type of BRS dysfunction was the dependent variable and polygraphic data were the independent variables, with adjustment for potential confounding factors such as sex, BMI, smoking and alcohol, diabetes, dyslipidaemia and hypertension.

Data were analysed using the Statistical Package for the Social Sciences version 17 for Windows (SPSS Inc., Chicago, IL, USA). All reported p-values are two-tailed, with the threshold of statistical significance set at $\mathrm{p}<0.05$.

\section{Results}

Table 1 shows the clinical, anthropometric, vascular and polygraphic data for the total sample and for women and men. Overall, participants had an average age of $66.9 \pm 0.9$ years with a female prevalence of $59 \%$ and a mean BMI of $25.5 \pm 3.8 \mathrm{~kg} \cdot \mathrm{m}^{-2}$. About $3 \%$ of the population had type 2 diabetes, $35 \%$ dyslipidaemia and $45 \%$ hypertension. Comparison analysis between sexes (table 1) revealed that women had lower values of BMI, neck circumference, SBP and DBP, and they were less frequently smokers or taking alcohol. In contrast, they had significantly lower values of AHI and indices of nocturnal hypoxaemia. Considering BRS, the mean values were in the normal range without sex differences. Table 2 reports the clinical, anthropometric and polygraphic data for subjects stratified according to AHI. Subjects without OSA (AHI $<15$ events $\cdot \mathrm{h}^{-1}$ ) represented $44 \%$ of the total population, with $35 \%$ labelled as mild-moderate $\left(\mathrm{AHI} \geqslant 15\right.$ events $\cdot \mathrm{h}^{-1}$ and $<30$ events $\left.\cdot \mathrm{h}^{-1}\right)$ and $21 \%$ as severe cases (AHI $\geqslant 30$ events $\left.\cdot \mathrm{h}^{-1}\right)$. Comparison analysis between groups revealed a tendency to progressive and significant increases in BMI, neck circumference, the number of subjects taking alcohol, prevalence of hypertension and high values of blood pressure paralleling the severity of AHI, and indices of nocturnal hypoxaemia with significant differences both in moderate $(\mathrm{p}=0.001)$ and severe $(\mathrm{p}<0.001)$ cases. Interestingly, no differences in BRS value were found between the three groups. Table 3 shows the clinical, anthropometric and polygraphic data according to BRS value. The majority of subjects had normal BRS (54\%), 36\% had mild impairment and $10 \%$ had severe blunted BRS. Subjects with severe BRS alteration (BRS $<3$ ) were those having a significant rise on the percentage of hypertension and all values of blood pressure examined $(\mathrm{p}<0.001)$, associated with an

\begin{tabular}{|c|c|c|c|c|}
\hline & Total & Women & Men & p-value \\
\hline Subjects $n$ & 801 & 462 & 339 & \\
\hline BMI $\mathrm{kg} \cdot \mathrm{cm}^{-2}$ & $25.5 \pm 3.8$ & $25.2 \pm 4.2$ & $26.0 \pm 3.0$ & 0.006 \\
\hline Neck circumference $\mathrm{cm}$ & $37.1 \pm 3.9$ & $34.6 \pm 2.6$ & $40.5 \pm 2.8$ & $<0.001$ \\
\hline Hypertension \% & 45.1 & 42.2 & 44.9 & 0.05 \\
\hline Diabetes \% & 2.5 & 1.3 & 4.3 & 0.008 \\
\hline Dyslipidaemia \% & 35 & 38 & 30 & $<0.001$ \\
\hline Alcohol \% & 46 & 32 & 61 & $<0.001$ \\
\hline Smoking \% & 26 & 12 & 66 & $<0.001$ \\
\hline SBP 24-h mmHg & $119.1 \pm 14.3$ & $116.6 \pm 13.7$ & $122.3 \pm 14.3$ & $<0.001$ \\
\hline DBP 24-h mmHg & $76.0 \pm 7.9$ & $74.2 \pm 7.6$ & $78.6 \pm 7.8$ & $<0.001$ \\
\hline SBP diurnal $\mathrm{mmHg}$ & $123.1 \pm 14.8$ & $121.3 \pm 14.8$ & $125.6 \pm 14.5$ & $<0.001$ \\
\hline DBP diurnal $\mathrm{mmHg}$ & $77.1 \pm 8.2$ & $75.6 \pm 8.2$ & $79.1 \pm 7.8$ & $<0.001$ \\
\hline SBP nocturnal $\mathrm{mmHg}$ & $106.9 \pm 15.5$ & $105.6 \pm 16.3$ & $108.8 \pm 14.2$ & 0.003 \\
\hline DBP nocturnal $\mathrm{mmHg}$ & $66.4 \pm 9.2$ & $64.6 \pm 9.1$ & $68.7 \pm 8.8$ & $<0.001$ \\
\hline BRS ms.mmHg ${ }^{-1}$ & $6.9 \pm 3.5$ & $7.0 \pm 3.5$ & $6.7 \pm 3.6$ & NS \\
\hline$A H I$ events $h^{-1}$ & $20.4 \pm 14.7$ & $16.7 \pm 12.4$ & $25.6 \pm 16.4$ & $<0.001$ \\
\hline ODI events $\cdot h^{-1}$ & $9.3 \pm 9.4$ & $7.4 \pm 7.7$ & $12.1 \pm 10.8$ & $<0.001$ \\
\hline Mean $\mathrm{SpO}_{2} \%$ & $95.3 \pm 1.7$ & $95.5 \pm 1.6$ & $95.1 \pm 1.9$ & 0.002 \\
\hline Minimal $\mathrm{SpO}_{2} \%$ & $89.7 \pm 4.1$ & $90.3 \pm 3.6$ & $89.0 \pm 4.0$ & $<0.001$ \\
\hline Time with $\mathrm{SpO}_{2}<90 \% \%$ & $1.9 \pm 5.7$ & $1.4 \pm 5.0$ & $2.6 \pm 6.6$ & 0.01 \\
\hline Respiratory AAl events $\cdot \mathrm{h}^{-1}$ & $15.6 \pm 10.5$ & $13.7 \pm 8.0$ & $18.3 \pm 12.2$ & $<0.001$ \\
\hline
\end{tabular}

Data are presented as mean \pm SD, unless otherwise stated. BMI: body mass index; SBP: systolic blood pressure; DBP: diastolic blood pressure; BRS: baroreceptor sensitivity; AHI: apnoea-hypopnoea index; ODI: oxygen desaturation index; $\mathrm{SpO}_{2}$ : oxygen saturation measured by pulse oximetry; AAl: autonomic arousal index; NS: nonsignificant. Significance was determined by t-test or Chi-squared difference between women and men. 
TABLE 2 Clinical, anthropometric and polygraphic data for the three groups of subjects stratified according to obstructive sleep apnoea severity

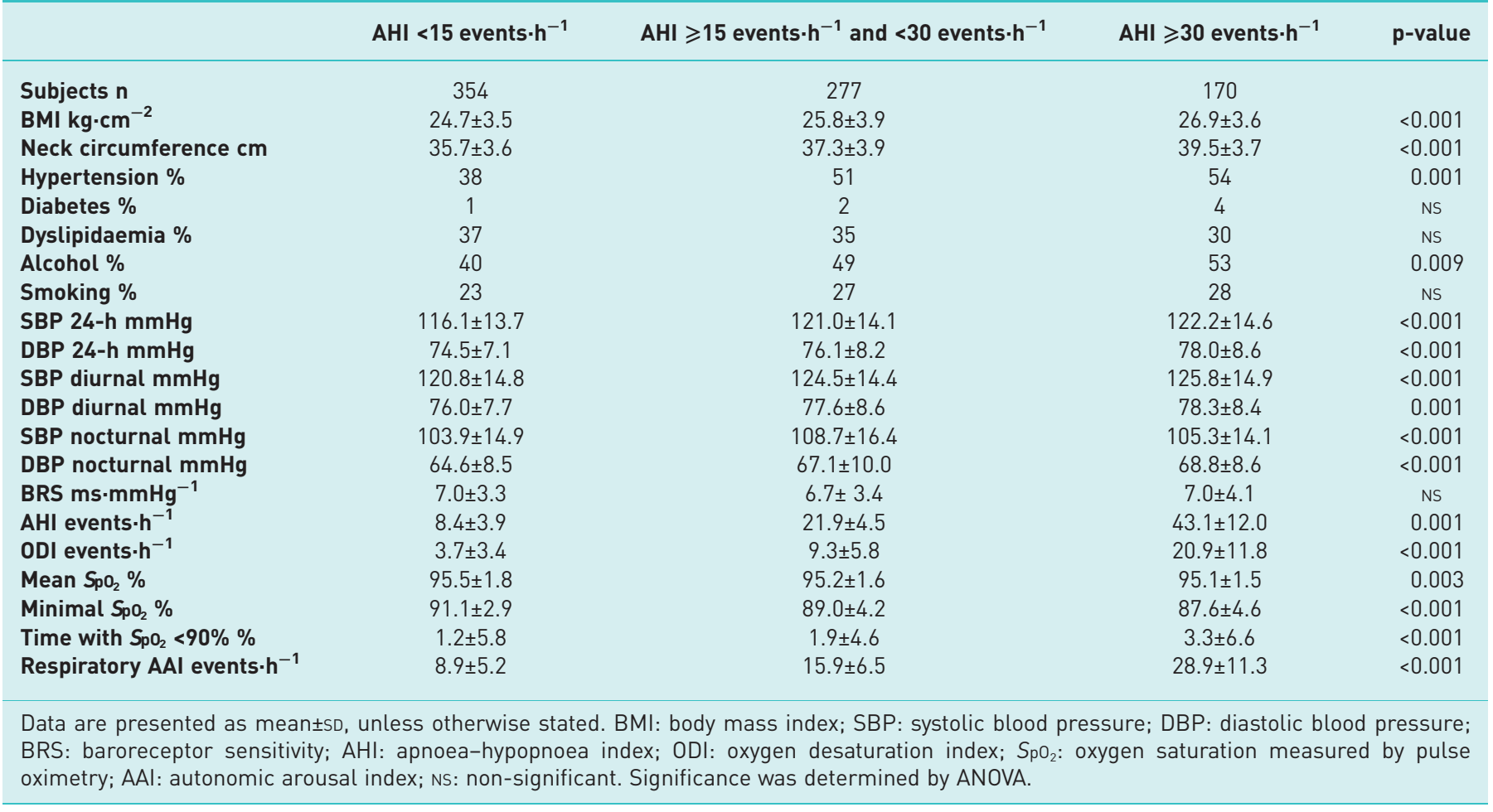

TABLE 3 Clinical, anthropometric and polygraphic data for the three groups of subjects stratified according to the baroreflex sensitivity threshold

\begin{tabular}{|c|c|c|c|c|}
\hline & $\mathrm{BRS}<3 \mathrm{~ms} \cdot \mathrm{mmHg}^{-1}$ & BRS $>3 \mathrm{~ms} \cdot \mathrm{mmHg}^{-1}$ and $<6 \mathrm{~ms} \cdot \mathrm{mmHg}^{-1}$ & $\mathrm{BRS}>6 \mathrm{~ms} \cdot \mathrm{mmHg}^{-1}$ & p-value \\
\hline Subjects $\mathbf{n}$ & 76 & 292 & 433 & \\
\hline $\mathrm{BMI} \mathbf{\mathrm { kg }} \cdot \mathrm{cm}^{-2}$ & $27.3 \pm 3.7$ & $25.5 \pm 3.8$ & $25.1 \pm 3.7$ & $<0.001$ \\
\hline Hypertension \% & 68 & 48 & 40 & $<0.001$ \\
\hline Diabetes \% & 4 & 4 & 1 & 0.03 \\
\hline Dyslipidaemia \% & 47 & 35 & 33 & NS \\
\hline SBP 24-h mmHg & $127.6 \pm 16.8$ & $120.0 \pm 13.9$ & $117.1 \pm 13.5$ & $<0.001$ \\
\hline DBP 24-h mmHg & $81.2 \pm 9.2$ & $76.1 \pm 7.6$ & $75.1 \pm 7.6$ & $<0.001$ \\
\hline SBP diurnal mmHg & $130.1 \pm 16.9$ & $123.5 \pm 15.7$ & $121.7 \pm 13.4$ & $<0.001$ \\
\hline DBP diurnal mmHg & $80.5 \pm 9.1$ & $76.8 \pm 8.7$ & $76.6 \pm 7.5$ & 0.001 \\
\hline SBP nocturnal $\mathrm{mmHg}$ & $115.1 \pm 13.7$ & $107.2 \pm 15.8$ & $105.3 \pm 15.2$ & $<0.001$ \\
\hline DBP nocturnal $\mathrm{mmHg}$ & $71.0 \pm 8.2$ & $66.1 \pm 9.7$ & $65.7 \pm 8.9$ & $<0.001$ \\
\hline Minimal $\mathrm{SpO}_{2} \%$ & $87.9 \pm 4.4$ & $89.7 \pm 3.9$ & $90.0 \pm 4.0$ & $<0.001$ \\
\hline Time with $\mathrm{SpO}_{2}<90 \% \%$ & $3.7 \pm 6.9$ & $2.0 \pm 6.4$ & $1.5 \pm 5.0$ & 0.006 \\
\hline Respiratory AAl events $\cdot \mathrm{h}^{-1}$ & $18.2 \pm 12.4$ & $15.4 \pm 10.3$ & $15.2 \pm 10.3$ & $<0.001$ \\
\hline
\end{tabular}


increase in alcohol intake and indices of hypoxaemia. No significant differences were found for all considered factors in subjects with normal or mild BRS impairment.With correlation analysis, the BRS value was negatively associated with BMI ( $\mathrm{r}=-0.98 ; \mathrm{p}=0.006), 24-\mathrm{h}$ systolic $(\mathrm{r}=-0.180 ; \mathrm{p}=0.001)$ and diastolic ( $r=-0.142 ; \mathrm{p}=0.001)$ blood pressures and with ODI $(\mathrm{r}=-0.08 ; \mathrm{p}=0.03)$. Multiple logistic regression analyses (table 4) adjusted for sex, BMI, diabetes, dyslipidaemia, hypertension, alcohol, smoking, AHI and ODI revealed that subjects with a BRS $<3$ were those with hypertension (OR 0.41; 95\% CI 0.24-0.81; $\mathrm{p}=0.002$ ) and overweight (OR 0.42; 95\%CI: 0.25-0.81; $\mathrm{p}=0.008$ ) without contribution of AHI and ODI.

\section{Discussion}

To the best of our knowledge, the present study is the first to evaluate the potential independent association between dysfunction of baroreceptor sensitivity and the presence of OSA in a large group of healthy elderly subjects. The main finding of our study was that severe BRS dysfunction was present in only $10 \%$ of the group, the majority having normal values (54\%). Moreover, the altered BRS affected mostly the severe OSA cases, without effect on snorers and mild-moderate subjects. A second interesting result is that neither smoking habit and alcohol consumption nor AHI and indices of hypoxaemia contributed to BRS dysregulation, with hypertension and obesity being the most important factors. Although speculative, we can suggest that BRS dysfunction in healthy elderly OSA reflects more of an autonomic dysfunction of the sympathetic-parasympathetic balance predisposing to hypertension rather than as a contributing factor of OSA vascular consequences.

It is known that, apart from the acute activation of sympathetic activation related to apnoea and arousal, persistent sleep fragmentation and repeated episodes of intermittent hypoxia-hypercapnia might induce not only a rise in the chemoreceptor sympathetic tone but also a downwards resetting of baroreceptor sensitivity [31] and its set-points, both reducing the cardio-protective effects of parasympathetic activity on the heart [32]. Despite an association between blunted BRS and hypertensive risk [17, 18] in OSA patients, controversial data are reported in the literature and are probably related to differences in methodology, sample size, definition of abnormal BRS and different study design. In initial studies performed during sleep $[18,33]$, BRS was depressed during daytime and night-time, but only in severe OSA cases. Moreover, despite studies performed after positive continuous positive pressure [20,34] and surgery [35] showing a BRS improvement, there was not a complete normalisation. Furthermore, if RYAN et al. [15] observed that the frequency of oxygen desaturation $>4 \%$ predicts decreased nocturnal BRS, this was not the case in children after adenotonsillectomy [41] and in our cases in whom any significant link was found between severity of hypoxaemia and BRS level. Overall, these data might suggest a threshold level of frequency and severity of hypoxaemia dips to induce a depressed BRS.

Another mechanism acting on cardiovascular risk in OSA patients is apnoea-related sleep fragmentation translated by arousals occurring at the end of apnoea, known to contribute to the dysfunction of the autonomic nervous system in OSA patients. Since our subjects had a polygraphic study that did not allow a correct estimation of sleep fragmentation, respiratory autonomic activations were analysed as surrogate markers of sleep disruption [36], and they were not associated with BRS. These results are supported by two

TABLE 4 Mutivariate stepwise regression models and p-value for the two type of baroreceptor sensitivity dysfunction

\begin{tabular}{|c|c|c|c|c|}
\hline \multirow[t]{2}{*}{ Explicative variables ${ }^{\#}$} & \multicolumn{2}{|c|}{$\begin{array}{l}\text { BRS }>3 \mathrm{~ms} \cdot \mathrm{mmHg}^{-1} \\
\text { and }<6 \mathrm{~ms} \cdot \mathrm{mmHg}^{-1}\end{array}$} & \multicolumn{2}{|c|}{ BRS $<3 \mathrm{~ms} \cdot \mathrm{mmHg}^{-1}$} \\
\hline & OR $(95 \% \mathrm{CI})$ & $p$-value & OR $(95 \% \mathrm{CI})$ & p-value \\
\hline Sex (women) & $0.63(0.34-1.21)$ & 0.16 & $0.70(0.39-1.31)$ & 0.26 \\
\hline Hypertension (yes) & $0.61(0.35-1.05)$ & 0.09 & $0.41(0.24-0.81)$ & 0.002 \\
\hline Dyslipidaemia (yes) & $0.61(0.35-1.08)$ & 0.07 & $0.63(0.37-1.1)$ & 0.09 \\
\hline Diabetes (yes) & $2.37(0.61-9.20)$ & 0.21 & $0.78(0.17-3.55)$ & 0.75 \\
\hline Alcohol (yes) & $1.23(0.47-1.47)$ & 0.22 & $0.83(0.47-1.48)$ & 0.54 \\
\hline Smoking (yes) & $0.84(0.39-1.27)$ & 0.42 & 0.71 (0.39-1.27) & 0.25 \\
\hline $\mathrm{BMI}^{\pi}\left(>25 \mathrm{~kg} \cdot \mathrm{m}^{-2}\right.$ and $\left.<30 \mathrm{~kg} \cdot \mathrm{m}^{-2}\right)$ & $0.59(0.21-1.00)$ & 0.08 & $0.45(0.25-0.81)$ & 0.008 \\
\hline $\mathrm{BMI}^{\pi}\left(>30 \mathrm{~kg} \cdot \mathrm{m}^{-2}\right)$ & $0.60(0.35-1.25)$ & 0.045 & $0.38(0.17-0.82)$ & 0.01 \\
\hline AHI $\left(>15\right.$ events $\left.\cdot h^{-1}\right)$ & $0.71(0.90-2.09)$ & 0.71 & $0.90(0.52-1.57)$ & 0.71 \\
\hline ODI (>15 events $\left.\cdot h^{-1}\right)$ & $0.88(0.52-1.57)$ & 0.49 & $1.05(0.52-2.10)$ & 0.88 \\
\hline
\end{tabular}


previous studies considering the vascular response to arousals during flow limitation [37] and apnoea [38] in healthy older subjects showing a blunted and delayed arousal response to respiratory events. Therefore, we can suggest that in healthy elderly the long duration of the disease may be considered as an ischaemic "preconditioning" [39] reducing the autonomic response to apnoea, hypoxic dip and arousals and contributing to lower mortality in older OSA.

Little attention has been given to the influence of ageing on BRS and few studies have demonstrated that cardiovagal BRS is blunted in normal ageing [14-16, 40], related to an age-related increase in basal sympathetic activity and the consequent reduction in tonic baroreflex suppression of the central sympathetic outflow. Taking into account that with ageing the prevalence of OSA increased [2-4] and BRS declined, we would expect a greater BRS dysfunction in our OSA elderly. Contrary to this expectation, no significant association was found between the level of BRS dysfunction and OSA, a blunted BRS present only in $10 \%$ of cases and without significant differences between subjects with normal BRS and those with a small impairment. An interesting finding is that subjects with greater BRS dysfunction were those having a slight rise in AHI and ODI but a stronger increase in BMI, hypertension, alcohol intake and dyslipidaemia, all factors $[18,24-26]$ known to affect BRS. These findings were confirmed by multivariate regression analysis showing the key role of obesity and hypertension on BRS dysfunction.

\section{Strengths and limitations}

The strengths of this study include the relatively large sample size with a near equal number of men and women, and an extensive evaluation including not only an objective estimation of BRS, AHI and hypoxaemia but also an analysis of confounder factors such as self-reported alcohol, smoking, diabetes, dyslipidaemia and hypertension, all known to affect BRS. However, we have to underline that our population is a very selective sample in which several exclusion criteria on reported cardiac, vascular and cerebral disease were applied. Thus, we have to recognise that the results obtained in our population may differ from those which would be obtained for elderly patients referred to sleep clinics, and underline the need to be replicated in large patient samples. Finally, as previously described, we did not perform polysomnography that would better estimate the role of sleep fragmentation and age-related sleep disturbances on BRS dysfunction.

\section{Conclusions}

This study has demonstrated that in healthy elderly with unrecognised OSA, the risk of blunted baroreceptor sensitivity was low, affecting only $10 \%$ of the sample and essentially in severe cases. In our population, neither the severity of hypoxaemic dips nor the OSA severity as defined by AHI explained the presence of an altered baroreceptor sensitivity, with obesity and hypertension playing key roles. These results need to be taken into account in longitudinal studies and in large populations in order to better define the link between OSA and the cardiovascular outcome in older people.

\section{References}

1 Young T, Peppard P, Gottlieb D. The epidemiology of obstructive sleep apnea: a population health perspective. Am J Respir Crit Care Med 2002; 165: 1217-1239.

2 Neikrug AB, Ancoli-Israel S. Sleep disorders in the older adult: a mini-review. Gerontology 2010; 56: 181-189.

3 Young T, Shahar E, Nieto FJ, et al. Predictors of sleep-disordered breathing in community dwelling adults: the Sleep Heart Health Study. Arch Intern Med 2002; 162: 893-900.

4 Mehra R, Stone KL, Blackwell T, et al. Prevalence and correlates of sleep-disordered breathing in older men: osteoporotic fractures in men sleep study. J Am Geriatric Soc 2007; 55: 1356-1364.

5 Peppard PE, Young T, Palta M, et al. Prospective study of the association between sleep disordered breathing and hypertension. N Engl J Med 2000; 342: 1378-1384.

6 Ding W, Zhou L, Bao Y, et al. Autonomic nervous function and baroreflex sensitivity in hypertensive diabetic patients. Acta Cardiol 2011; 66: 465-470.

7 Dauphinot V, Gosse P, Kossovsky MP, et al. Autonomic nervous system activity is independently associated with the risk of shift in the non-dipper blood pressure pattern. Hypertens Res 2010; 33: 1032-1037.

8 Shamsuzzaman AS, Gersh BJ, Somers VK. Obstructive sleep apnea: implications for cardiac and vascular disease. JAMA 2003; 290: 1906-1914.

9 Somers VK, Dyken ME, Clary MP, et al. Sympathetic neural mechanisms in obstructive sleep apnea. J Clin Invest 1995; 96: 1897-1904.

10 Gozal D, Kheirandish L. Cardiovascular morbidity in obstructive sleep apnea: oxidative stress, inflammation and much more. Am J Respir Crit Care Med 2008; 177: 369-375.

11 Del Rio R, Moya EA, Parga MJ, et al. Carotid body inflammation and cardiorespiratory alteration in intermittent hypoxia. Eur Respir J 2012; 39: 1492-1500.

12 Lohmeier TE, Irwin DE, Rossing MA, et al. Prolonged activation of the baroreflex produces sustained hypotension. Hypertension 2004; 43: 306-311.

13 Hesse C, Charkoudian N, Jonyer MJ, et al. Baroreflex sensitivity inversely correlates with ambulatory blood pressure in normotensive humans. Hypertension 2007; 50: 41-46.

14 Carlson JT, Hedner JA, Seligren J, et al. Depressed baroreflex sensitivity in patients with obstructive sleep apnea. Am J Respir Crit Care Med 1996; 154: 1490-1496. 
15 Ryan S, Ward S, Heneghan C, et al. Predictors of decreased spontaneous baroreflex sensitivity in obstructive sleep apnea syndrome. Chest 2007; 131: 1100-1107.

16 Noda A, Nakata S, Koike Y, et al. Continuous positive airway pressure improves daytime baroreflex sensitivity and nitric oxide production in patients with moderate to severe obstructive sleep apnea syndrome. Hypertens Res 2007; 30: 669-676

17 Bonsignore MR, Parati G, Insalaco G, et al. Baroreflex control of heart rate during sleep in severe obstructive sleep apnea: Effects of acute CPAP. Eur Respir J 2006; 27: 128-135.

18 Blomster H, Laitinien TP, Hartikainen JEK, et al. Mild obstructive sleep apnea does not modulate baroreflex sensitivity in adults patients. Nat Sci Sleep 2015; 7: 73-80.

19 Gates GJ, Mateika SE, Basner RC, et al. Baroreflex sensitivity in nonapneic snorers and control subjects before and after nasal continuous positive airway pressure. Chest 2004; 126: 801-807.

20 Schobel C, Fietze I, Glos M, et al. Nocturnal snoring decreased daytime baroreceptor sensitivity. Respir Med 2014; 108: 1049-1055.

21 Laitinen T, Hartikainen J, Niskanen L, et al. Age and gender dependency of baroreflex sensitivity in healthy subjects. J Applied Physiol 1998; 84: 576-583.

22 Fisher JP, Areum K, Colin NY, et al. Influence of aging on carotid baroreflex peak response latency in humans. J Physiol 2009; 587: 5427-5439.

23 Parker Jones P, Christou DD, Jordan J, et al. Baroreflex buffering is reduced with age in healthy men. Circulation 2003; 107: 1770-1774.

24 Gerhardt U, Vorneweg P, Riedasch M, et al. Acute and persistent effects of smoking on the baroreceptor function. J Auton Pharmacol 1999; 19: 105-108.

25 Kardos A, Watterich G, De Menenez R, et al. Determinants of spontaneous baroreflex sensitivity in a healthy working population. Hypertension 2001; 37: 911-916.

26 Barthélémy JC, Pichot V, Dauphinot V, et al. Autonomic nervous system activity and decline as prognostic indicators of cardiovascular and cerebrovascular events: the 'PROOF' Study. Neuroepidemiology 2007; 29: 18-28.

27 Pickering TG, Hall JE, Appel LJ, et al. Subcommittee of professional and public education of American Heart Association Council on high blood pressure research. Recommendations for blood pressure measurement in humans and experimental animals. Part 1: blood pressure measurement in humans: a statement for professionals from the Subcommittee of professionals and public education of the American Heart Association Council on high blood pressure research. Hypertension 2005; 45: 142-161

28 Costes F, Roche F, Pichot V, et al. Influence of exercise training on cardiac baroreflex sensitivity in patients with COPD. Eur Respir J 2004; 23: 396-340.

29 Pitson DJ, Stradling JR. Autonomic markers of arousal during sleep in patients undergoing investigation for obstructive sleep apnea: relationships to EEG arousals, respiratory events and subjective sleepiness. J Sleep Res 1998; 7: 53-59.

30 Pavlova MK, Duffy JF, Shea SA. Polysomnographic respiratory abnormalities in asymptomatic individuals Sleep 2008; 31: 241-248.

31 Cooper VL, Elliot MW, Pearson SB, et al. Daytime variability of baroreflex function in patients with obstructive sleep apnoea: implication for hypertension. Exp Physiol 2007; 92: 391-398.

32 Dyavanapally J, Jameson $\mathrm{H}$, Dergacheva $\mathrm{O}$, et al. Chronic intermittent hypoxia-hypercapnia blunts heart rate responses and alters neurotransmission to cardiac vagal neurons. J Physiol 2014; 592: 2799-2811.

33 Parati G, DiRienzo M, Bonsignore MR, et al. Autonomic cardiac regulation in obstructive sleep apnea syndrome: evidence from spontaneous baroreflex analysis during sleep. J Hypertens 1997; 12: 1621-1626.

34 Bonsignore MR, Parati G, Insalaco G, et al. Continuous positive airway pressure treatment improves baroreflex control of heart rate during sleep in severe obstructive sleep apnea syndrome. Am J Respir Crit Care Med 2002 166: $279-286$.

35 Huang CC, Lin WC, Chen HL, et al. Improvement of baroreflex sensitivity in patients with obstructive sleep apnea following surgical treatment. Clin Neurophysiol 2016; 127: 544-550.

36 Chouchou F, Sforza E, Celle S, et al. Pulse transit time in screening sleep disordered breathing in an elderly population: the PROOF-SYNAPSE study. Sleep 2011; 34: 1051-1059.

37 Goff EA, Nicholas CL, Kleiman J, et al. The effect of flow limitation on the cardiorespiratory response to arousal from sleep under controlled conditions of chemostimulation in healthy older adults. J Sleep Res 2012; 21: 718-723.

38 Goff EA, Priscoll DM, Simonds AK, et al. The cardiovascular response to arousal from sleep decrease with age in healthy adults. Sleep 2008; 31: 1009-1017.

39 Almendros I, Wang Y, Gozal D. The polymorphic and contradictory aspects of intermittent hypoxia. Am J Physiol Lung Cell Mol Physiol 2014; 307: L129-L140.

40 Monahan KD, Dinenno FA, Seals DR, et al. Age-associated changes in cardiovagal baroreflex sensitivity are related to central arterial compliance. Am J Physiol Heart Circ Physiol 2001; 281: H284-H289.

41 Crisalli JA, McConnell K, Vandyke RD, et al. Baroreflex sensitivity after adenotonsillectomy in children with obstructive sleep apnea during wakefulness and sleep. Sleep 2012; 35: 1335-1343. 